\title{
Thermal Management and Reliability of Power Electronics and Electric Machines
}

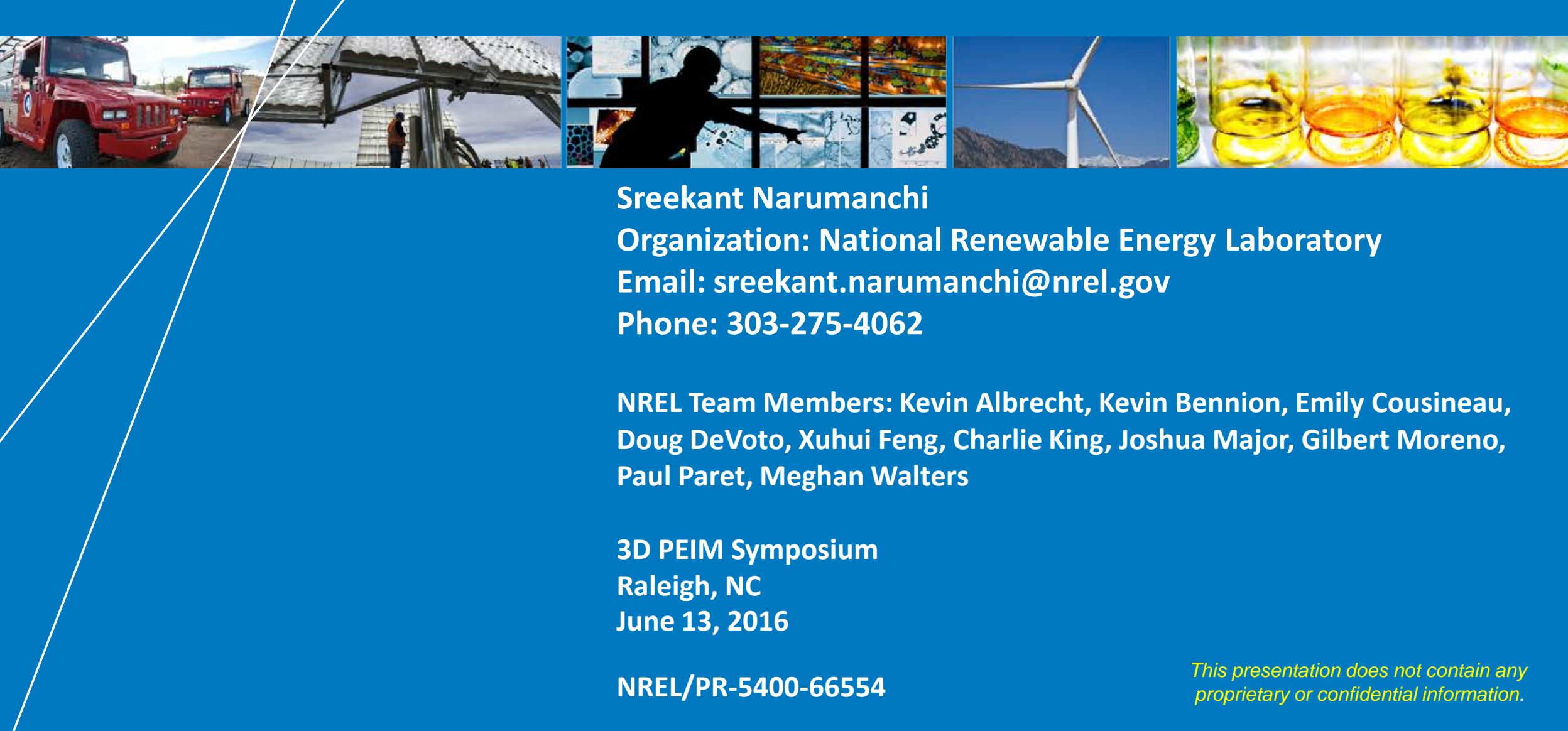




\section{Importance of Thermal Management and Reliability}

- Excessive temperature degrades the performance, life, and reliability of power electronics and electric machines.

- Advanced thermal management technologies enable

o Keeping temperature within limits

o Higher power densities

o Lower cost materials, configurations and system.

- Improve lifetime/reliability and develop new predictive lifetime models. 


\section{DOE Vehicle Technologies Office Electric Drive Technologies (EDT) Program Targets}

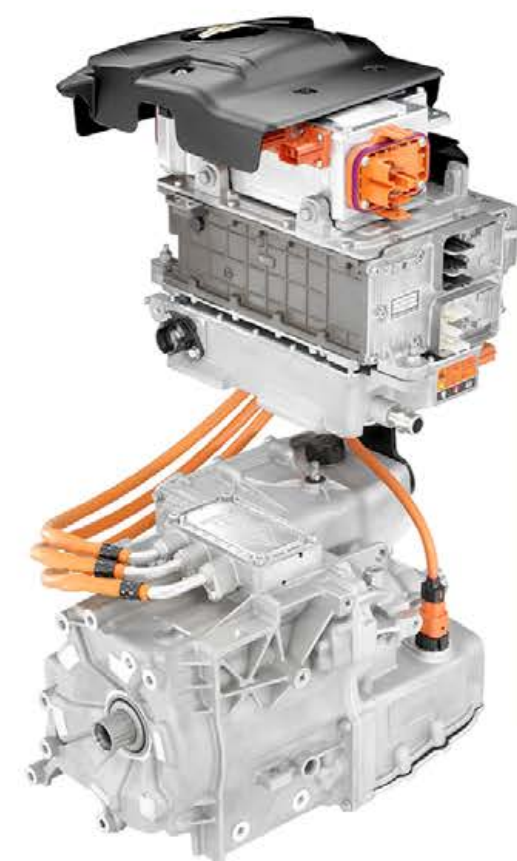

\section{Electric Drive System}

$\$ 30 / \mathrm{kW}, 1.1 \mathrm{~kW} / \mathrm{kg}, 2.6 \mathrm{~kW} / \mathrm{L}$

$90 \%$ system efficiency

(on-road status)

- Discrete Components

- Silicon Semiconductors

- Rare-Earth Motor Magnets

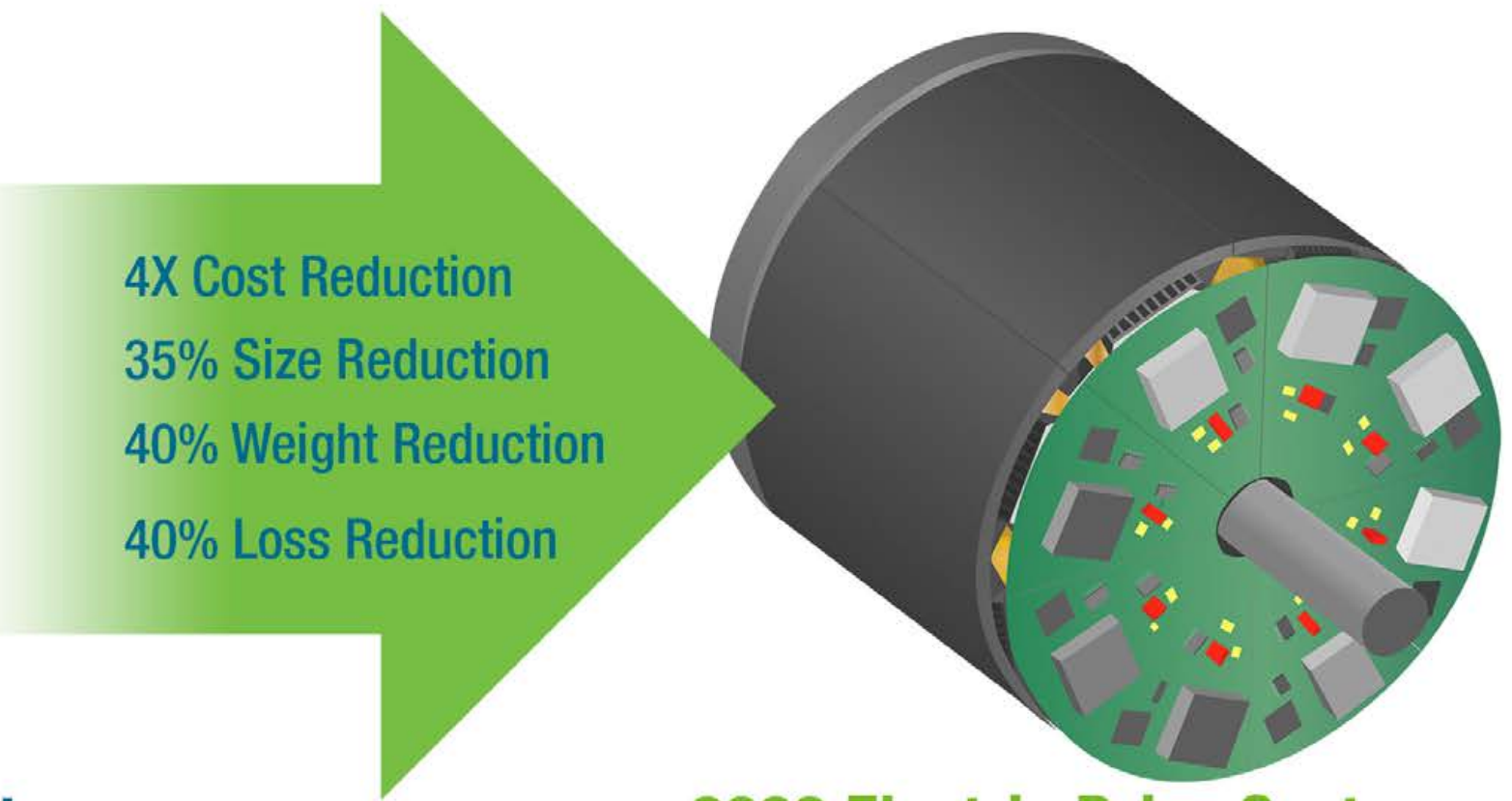

2022 Electric Drive System

$\$ 8 / \mathrm{kW}, 1.4 \mathrm{~kW} / \mathrm{kg}, 4.0 \mathrm{~kW} / \mathrm{L}$

94\% system efficiency

- Fully Integrated Components

- Wide-Bandgap (WBG) Semiconductors

- Non Rare-Earth Motors

From DOE EV Everywhere Grand Challenge Blueprint,

http://energy.gov/sites/prod/files/2016/05/ł31/eveverywhere_blueprint.pdf 


\section{NREL EDT Research Focus Areas}

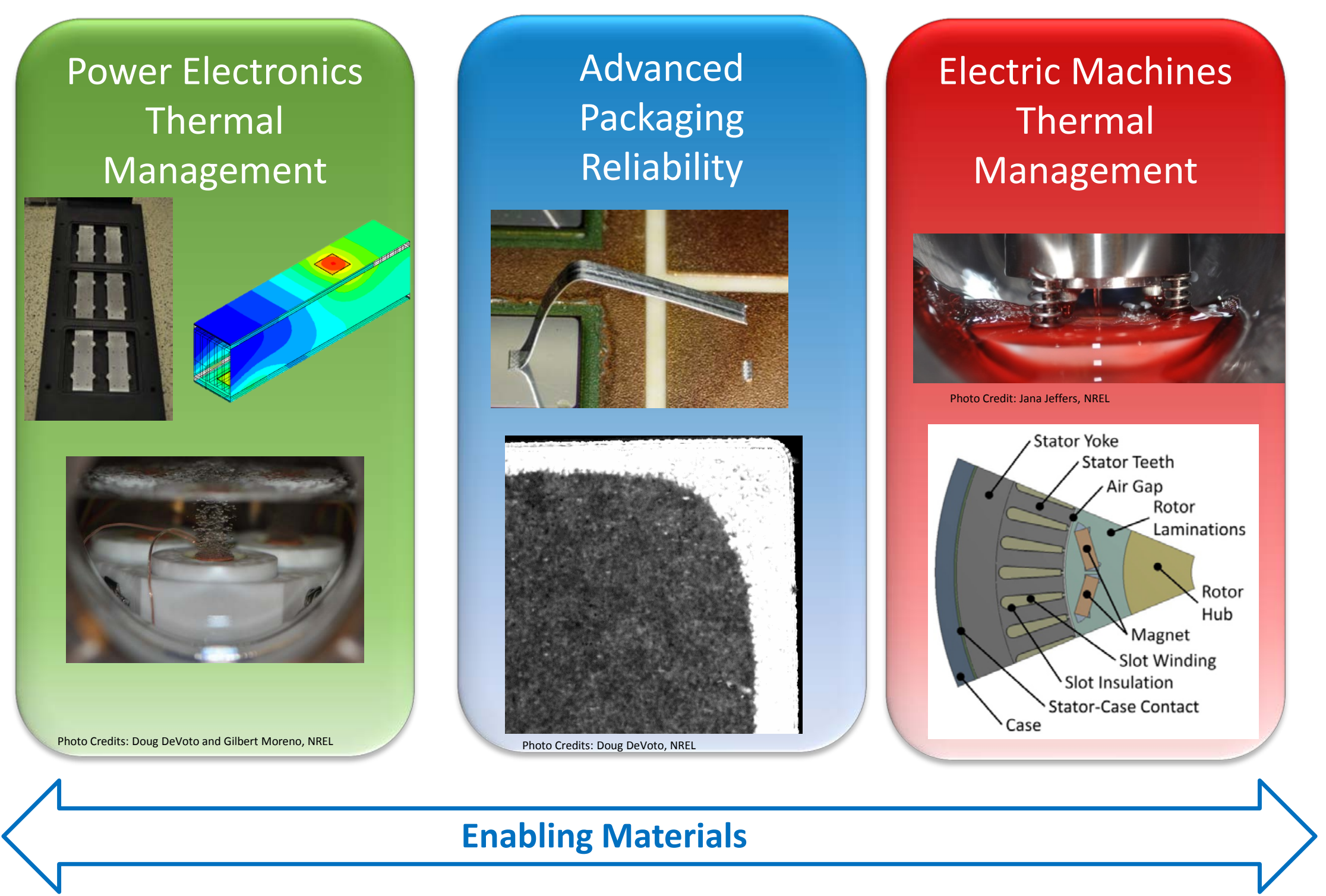

Research Focus Areas Will Reduce Cost, Improve Performance and Reliability 


\section{Power Electronics Thermal Management}




\section{Power Electronics Thermal Management Strategy}

- Packages based on WBG devices require advanced materials, interfaces, and interconnects

o Higher temperature capability

o Higher effective thermal conductivity

- Low-cost techniques to increase heat transfer rates

o Coolants - water-ethylene glycol (WEG), air, transmission coolant, refrigerants

o Enhanced surfaces

o Flow configurations

- System-level thermal management (capacitor and other passives)

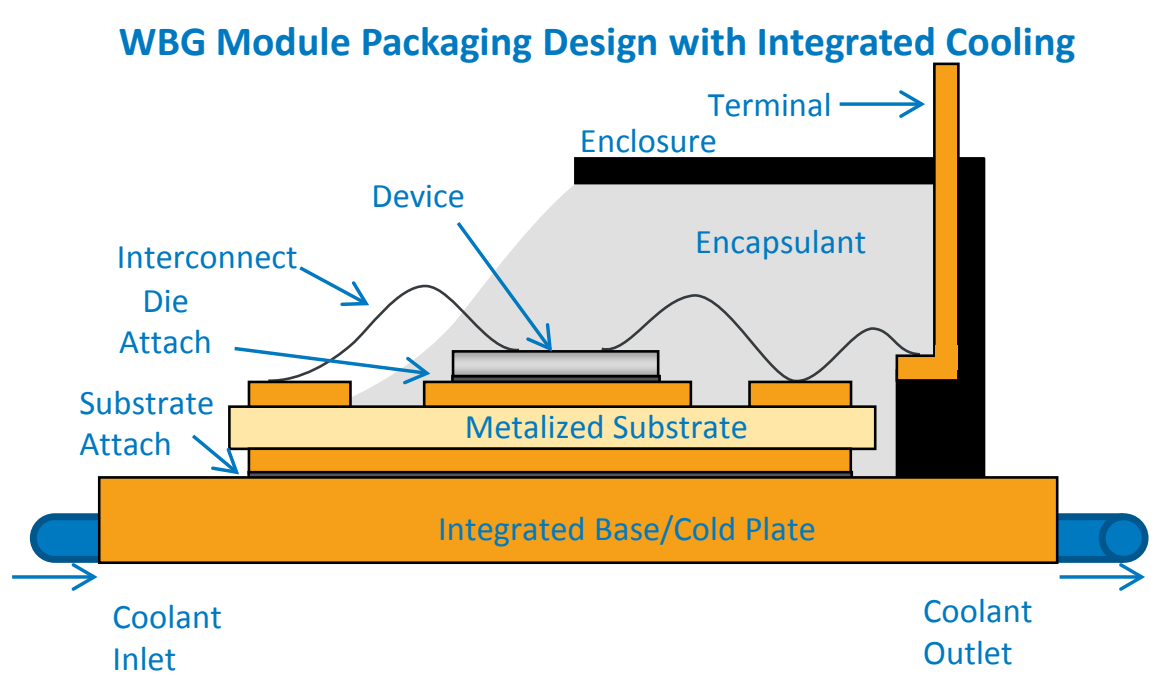




\section{The Challenge with Interfaces/Interface Materials}

- Interfaces can pose a major bottleneck to heat removal.

- Bond materials, such as solder, degrade at higher temperatures and are prone to thermomechanical failure.

- Problem can become more challenging for configurations employing WBG devices.
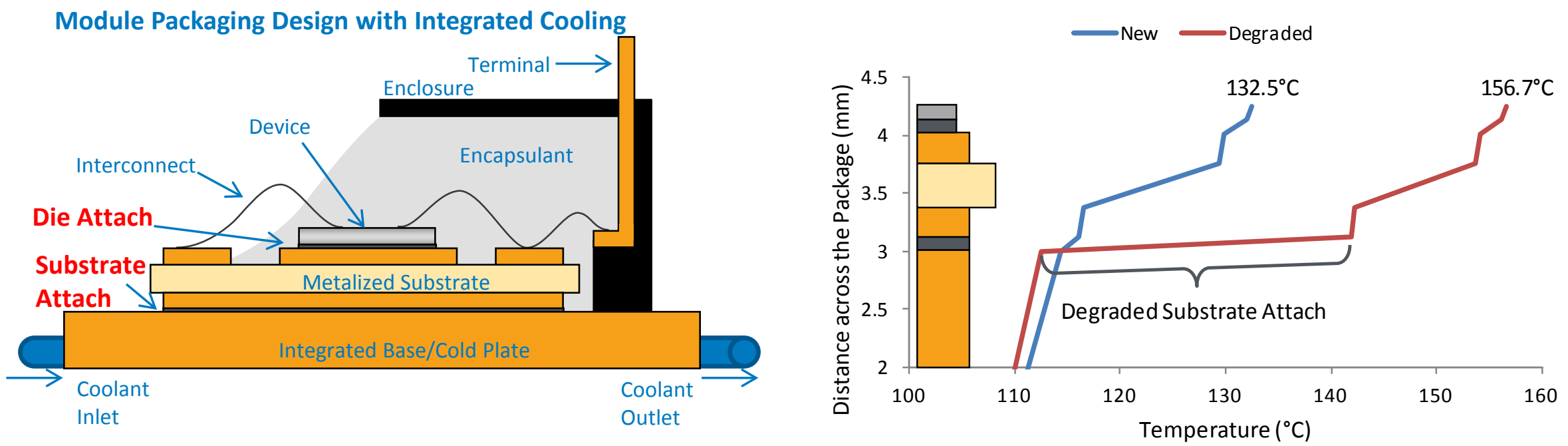
Thermal Resistance of Thermoplastics with Embedded Carbon Fibers

\begin{tabular}{|l|c|} 
& $\begin{array}{c}\text { Thermoplastic } \\
\text { film } \\
\text { HM-2 }\end{array}$ \\
\hline $\begin{array}{l}\text { Bondline } \\
\text { thickness }(\mu \mathrm{m})\end{array}$ & 60 \\
\hline $\begin{array}{l}\text { Bulk thermal } \\
\text { conductivity } \\
(\mathrm{W} / \mathrm{m} \cdot \mathrm{K})\end{array}$ & $37.5 \pm 6.8$ \\
\hline $\begin{array}{l}\text { Contact } \\
\text { resistance } \\
\left(\mathrm{m} \mathrm{m}^{2} \cdot \mathrm{K} / \mathrm{W}\right)\end{array}$ & $3.1 \pm 1.1$ \\
\hline $\begin{array}{l}\text { Total thermal } \\
\text { resistance } \\
\left(\mathrm{mm}^{2} \cdot \mathrm{K} / \mathrm{W}\right)\end{array}$ & $7.5 \pm 1.9$ \\
\hline
\end{tabular}

Frequency-domain transient thermoreflectance experiment configuration

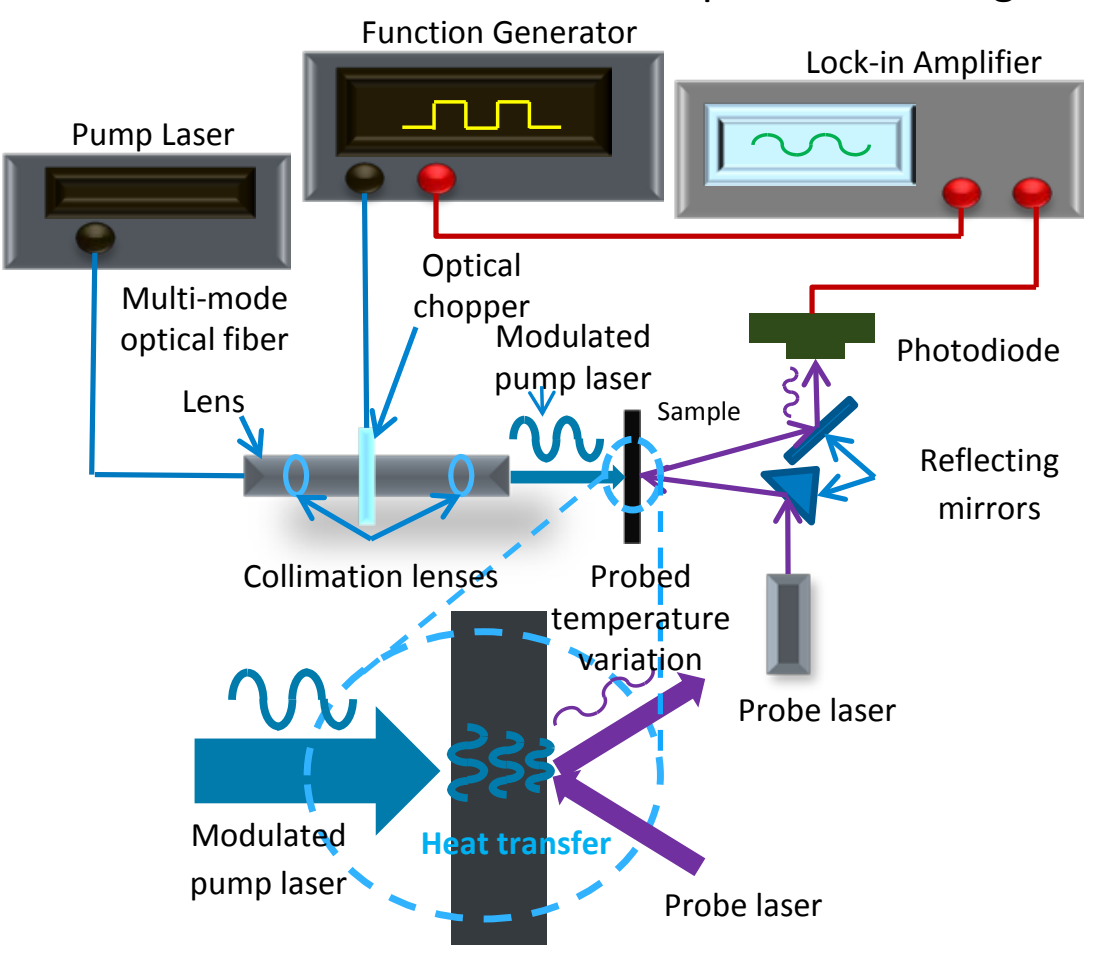

- Thermoplastics with embedded carbon fibers show very good thermal performance

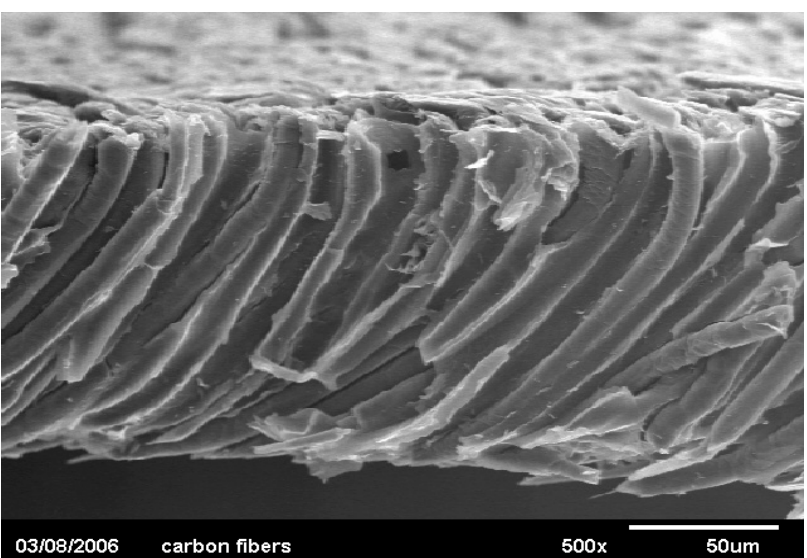

Photo: Courtesy of BtechCorp 


\section{Other Bonded Interface Materials}

- Bonded interface resistance in the range of 0.4 to $2 \mathrm{~mm}^{2} \mathrm{~K} / \mathrm{W}$ is possible.

D Materials developed in the DARPA programs are in this range.

o Copper nanowires

o Boron-nitride nanosheets $\left(0.4 \mathrm{~mm}^{2} \mathrm{~K} / \mathrm{W}\right.$ for 30 - to $50-\mu \mathrm{m}$ bondline thickness)

0 Copper nanosprings ( $1 \mathrm{~mm}^{2} \mathrm{~K} / \mathrm{W}$ for $50-\mu \mathrm{m}$ bondline thickness with very good reliability)

o Graphite solder

o Nanotube-based 


\section{Integrated Module Heat Exchanger}

NREL integrated module heat exchanger Patent No.: US 8,541,875 B2
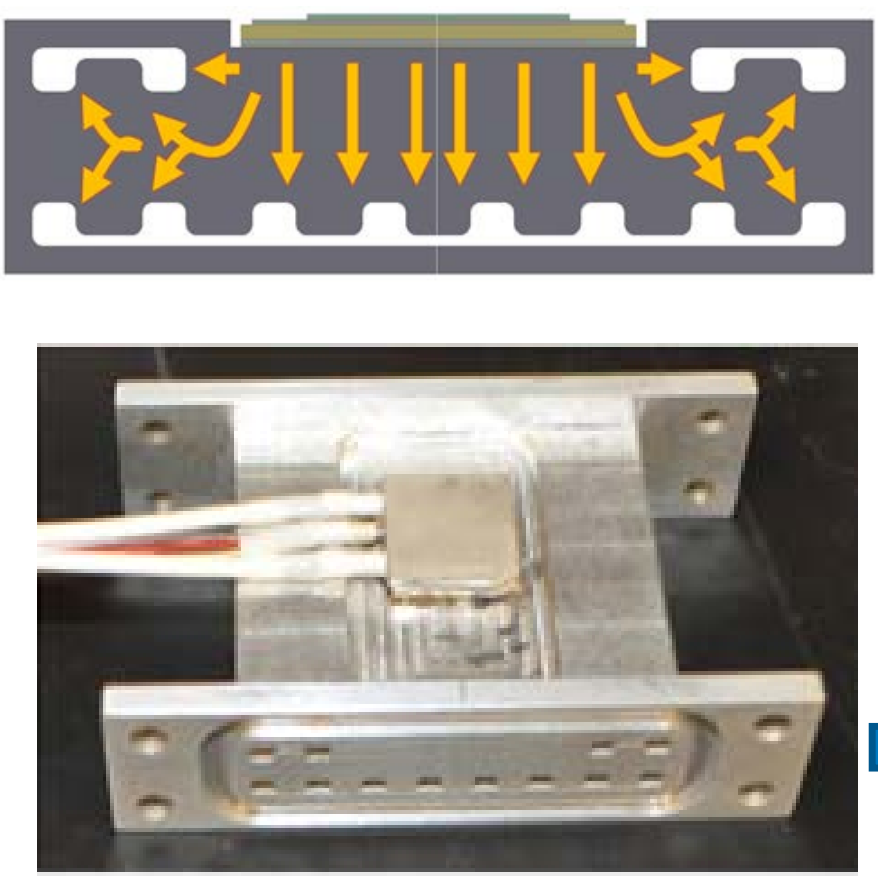

Photo Credits: Kevin Bennion, NREL
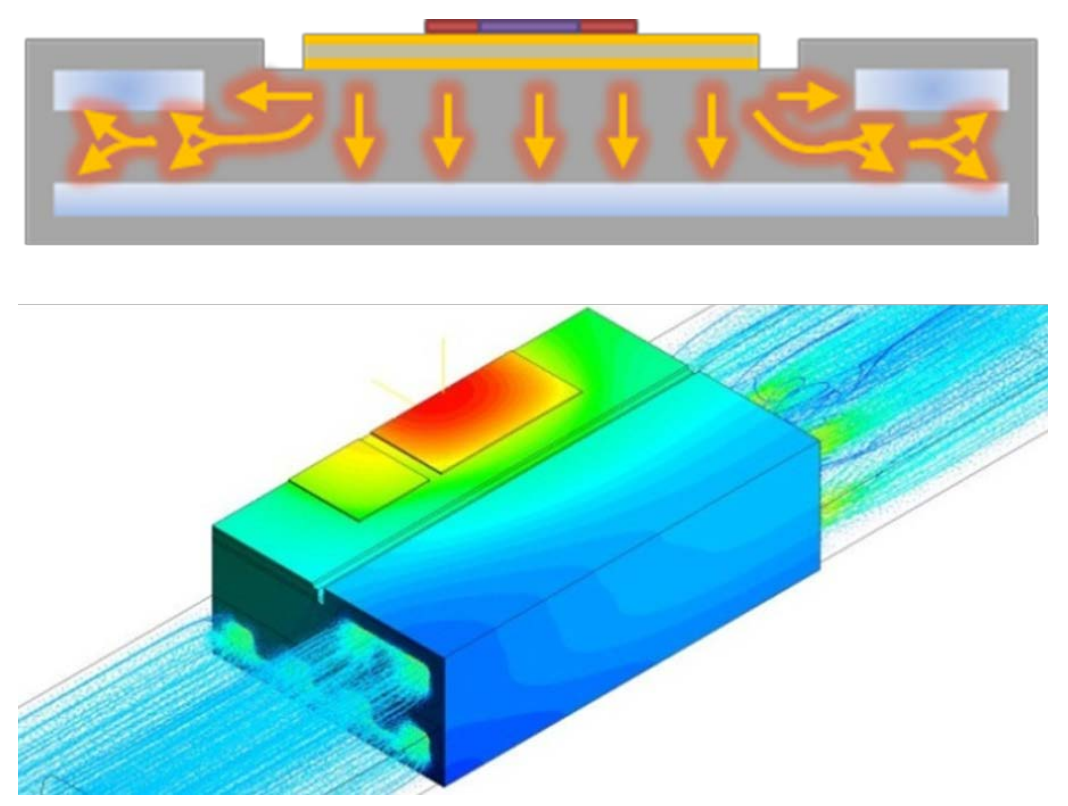

- Up to $100 \%$ increase in power per die area

- Up to $34 \%$ increase in coefficient of performance (efficiency) 


\section{Two-Phase Cooling for Power Electronics}

Fundamental

Research
Module-Level

Research
Inverter-Scale

Demonstration

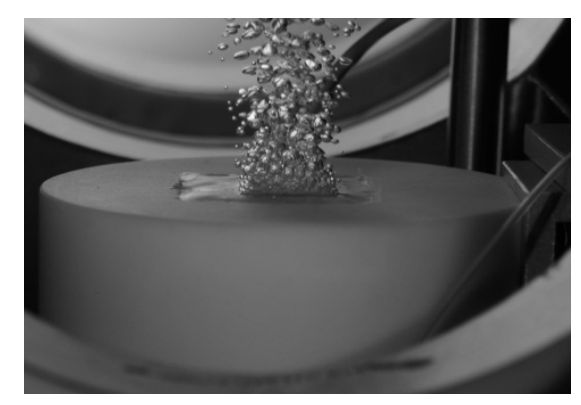

Photo Credit: Gilbert Moreno, NREL

Characterized performance of HFO-1234yf and HFC-245fa

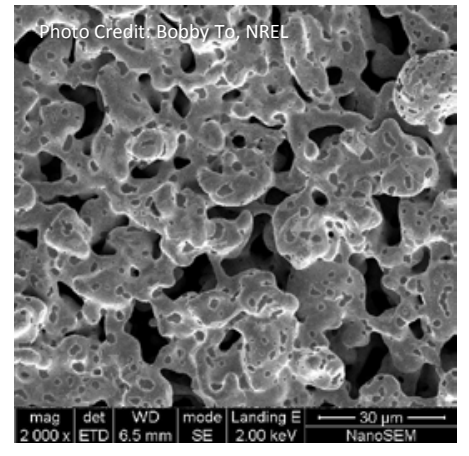

Achieved heat transfer rates of up to $200,000 \mathrm{~W} / \mathrm{m}^{2}-\mathrm{K}$

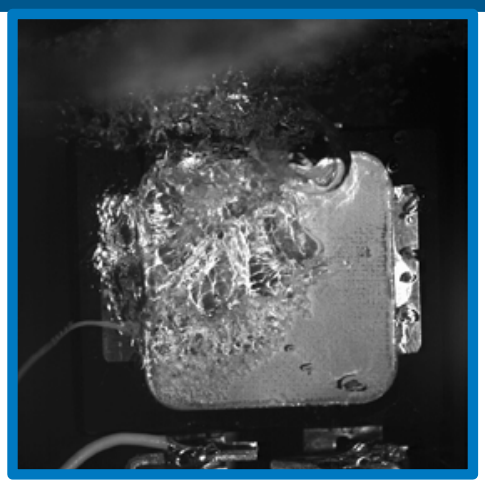

Photo Credit: Gilbert Moreno, NREL

Reduced thermal resistance by over $60 \%$ using immersion twophase cooling of a power module

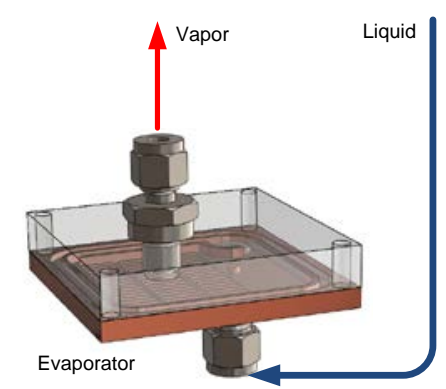

Quantified refrigerant volume requirements

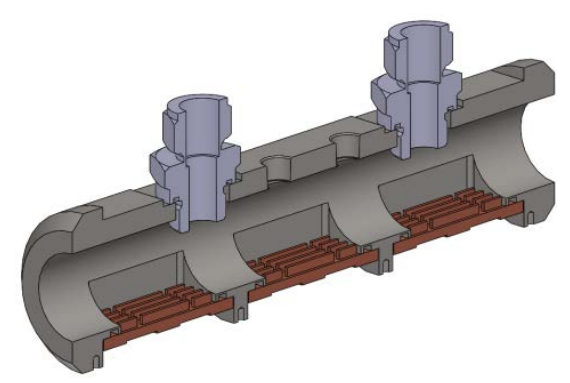

Dissipated $3.5 \mathrm{~kW}$ of heat with only $250 \mathrm{~mL}$ of refrigerant

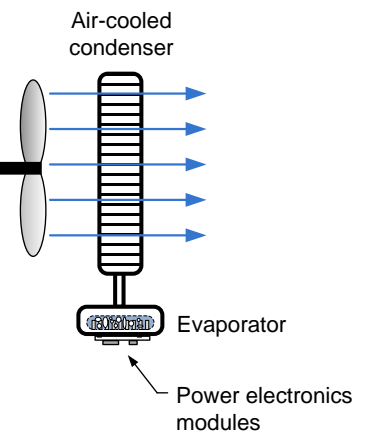

Predicted 58\%-65\% reduction in thermal resistance via indirect and passive two-phase cooling 


\section{WBG Power Electronics Thermal Management}

Create thermal models of an automotive inverter

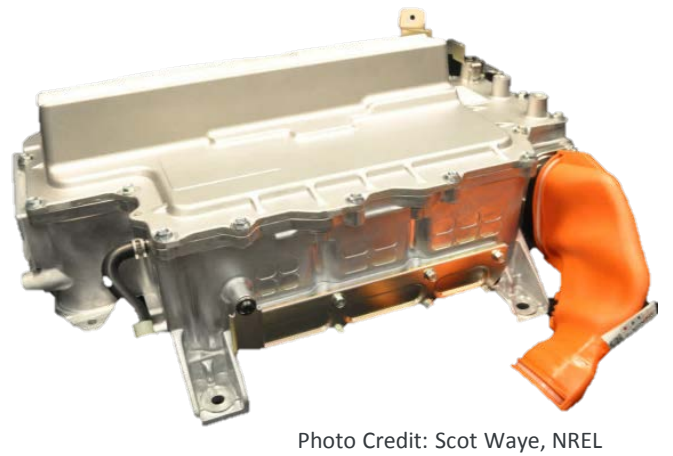

Validate the thermal models

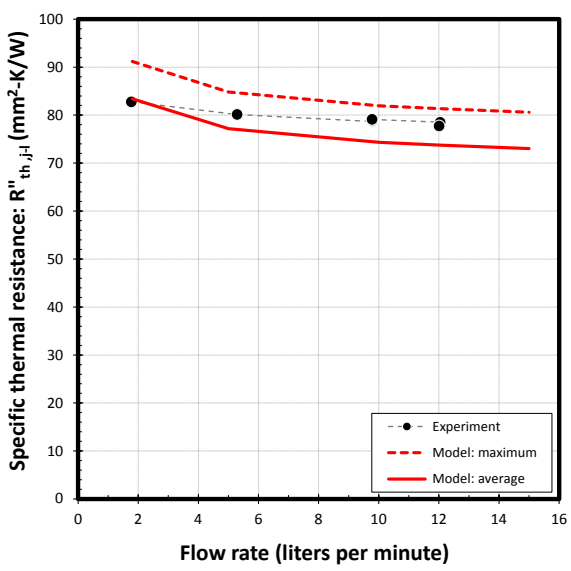

Simulate WBG operation using the inverter model

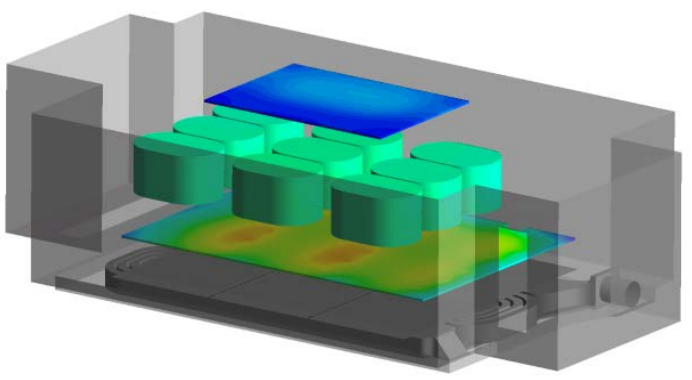

Quantify the inverter component temperatures under elevated device temperatures

Identify the primary thermal paths through which heat is conducted from the devices to the other components
Explore advanced cooling strategies
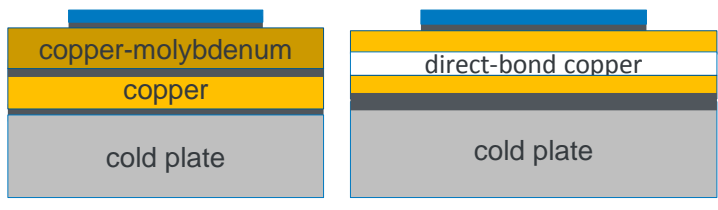

Evaluate different module topologies

Develop thermal management concepts to enable WBG power electronics

Experimentally validate some key thermal management concepts 


\section{Advanced Packaging Reliability}




\section{Bonded Interface Material Reliability}

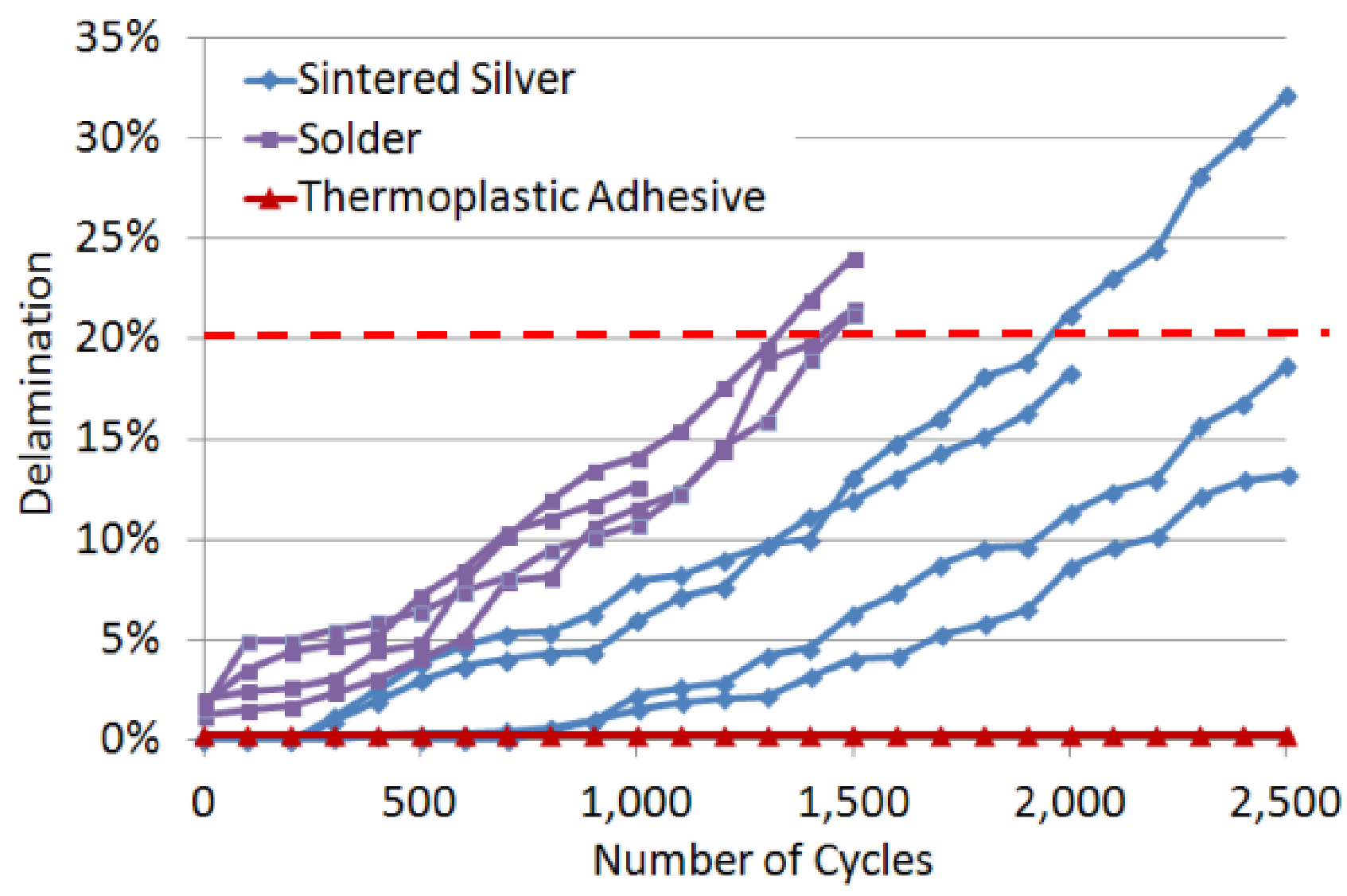

- Thermoplastics yield very good reliability

- Reliability of sintered silver is better than solder 


\section{Impact of Geometric Variations on Reliability}

- Joint Thickness

$\begin{array}{cc}\text { Profile } & \text { Joint Thickness } \\ (\mu \mathrm{m}) & \Delta \mathrm{W}(\mathrm{MPa})\end{array}$
Predictive Lifetime Model, $N_{f}=2312.5(\Delta W)^{-1.645}$

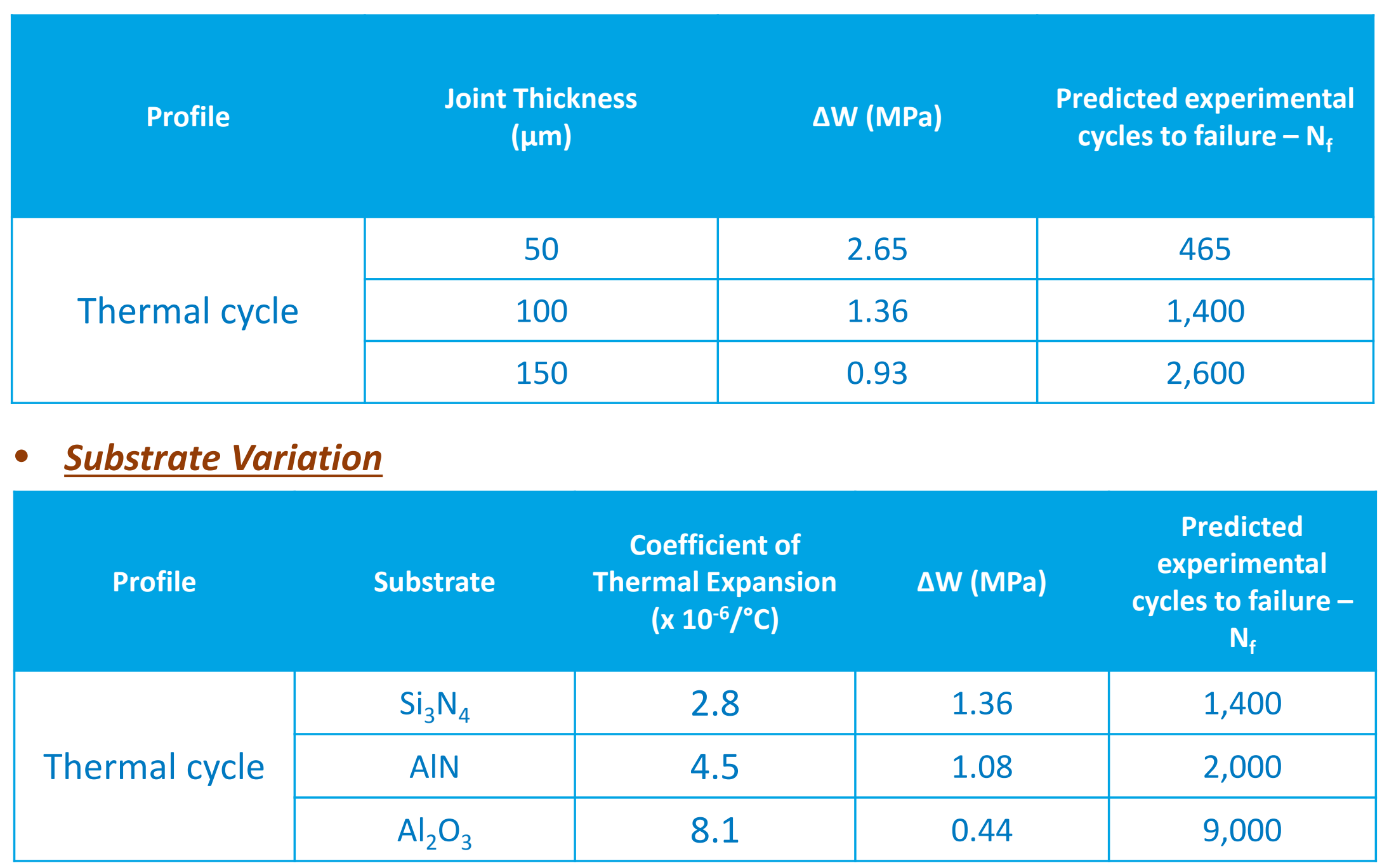




\section{Electric Machines Thermal Management}




\section{Electric Machines Thermal Management Strategy}

\section{Problem}

- Multiple factors impacting heat transfer are not well quantified or understood.

\section{Contributing Factors}

1. Direction-dependent thermal conductivity of lamination stacks

2. Direction-dependent thermal conductivity of slot windings and end windings

3. Thermal contact resistances (statorcase contact, slot-winding interfaces)

4. Convective heat transfer coefficients for ATF cooling

5. Cooling jacket performance

\section{Motor Cooling Section View}

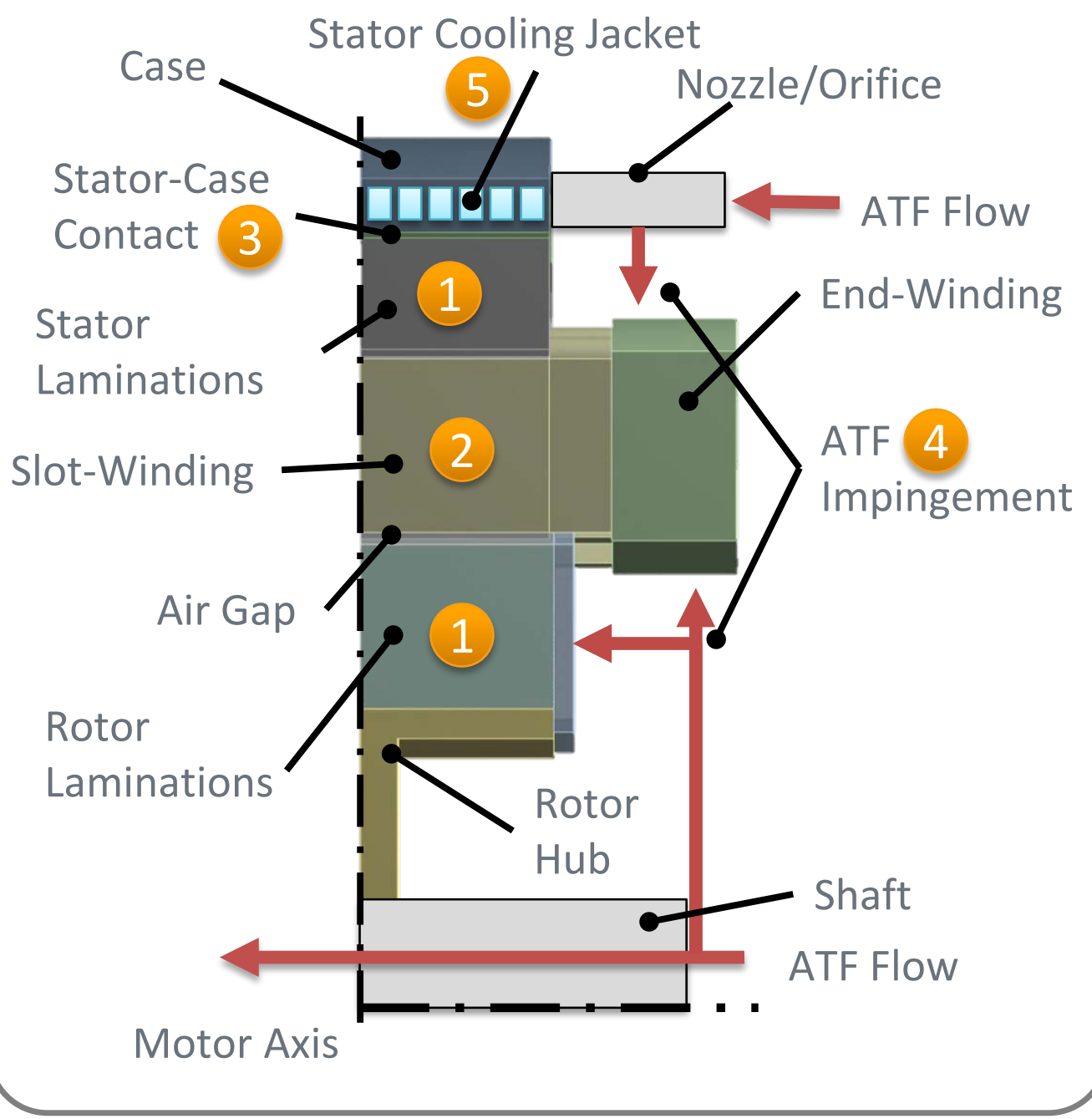

DOE APEEM FY14 Kickoff Meeting 


\section{Transmission Oil Jet Heat Transfer Characterization}

$50^{\circ} \mathrm{C}$ Inlet Temperature

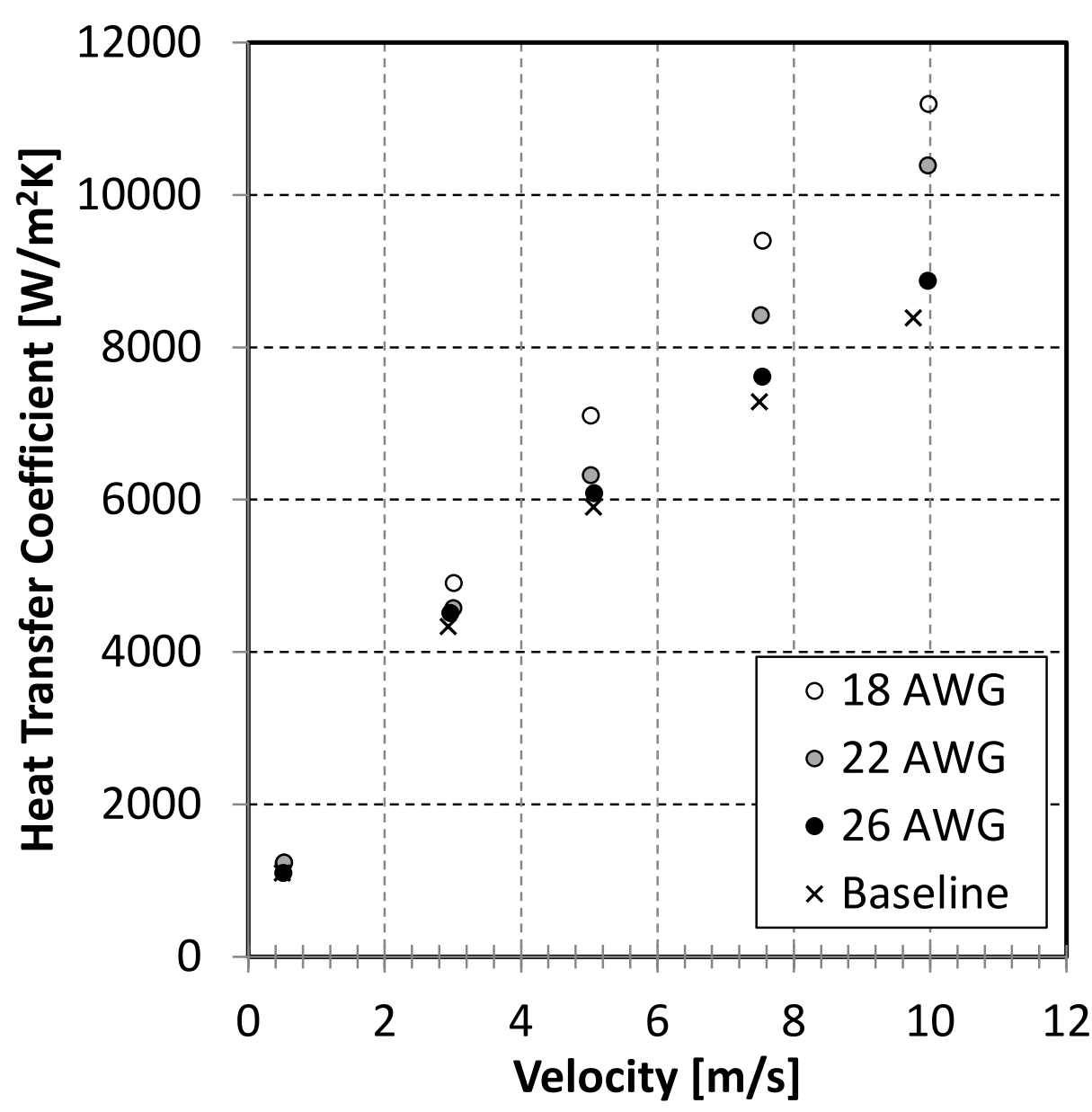

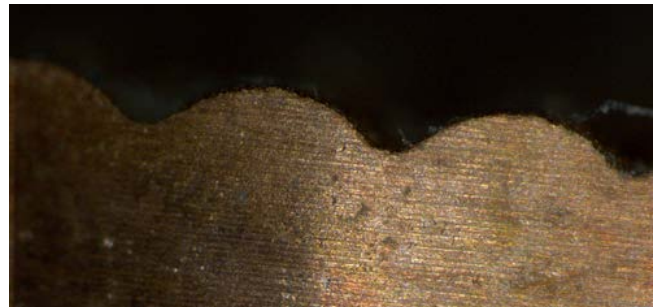

Side View

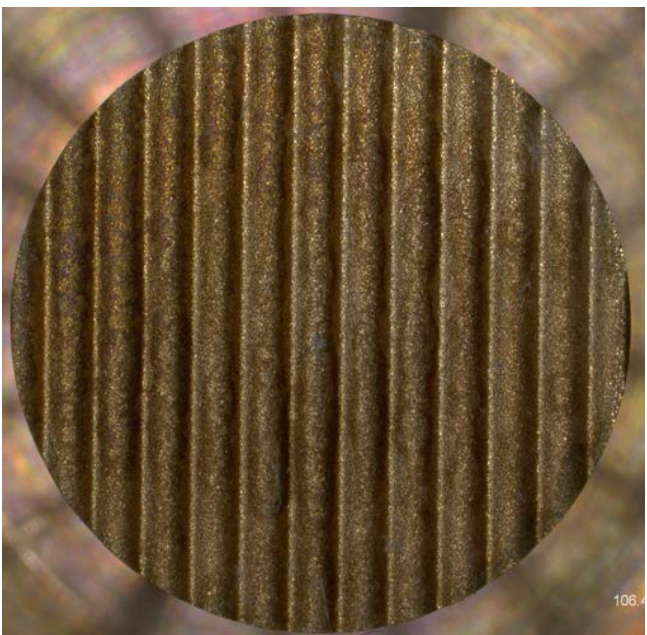

Top View
18 AWG surface target

Heat transfer coefficients of all target surfaces at $50^{\circ} \mathrm{C}$ inlet temperature

- Surface features increase heat transfer 


\section{Lamination Stack Effective Thermal Conductivity}

Measured Stack Thermal Resistance
Lamination-to-Lamination

Thermal Contact Resistance
Effective Through-Stack

Thermal Conductivity

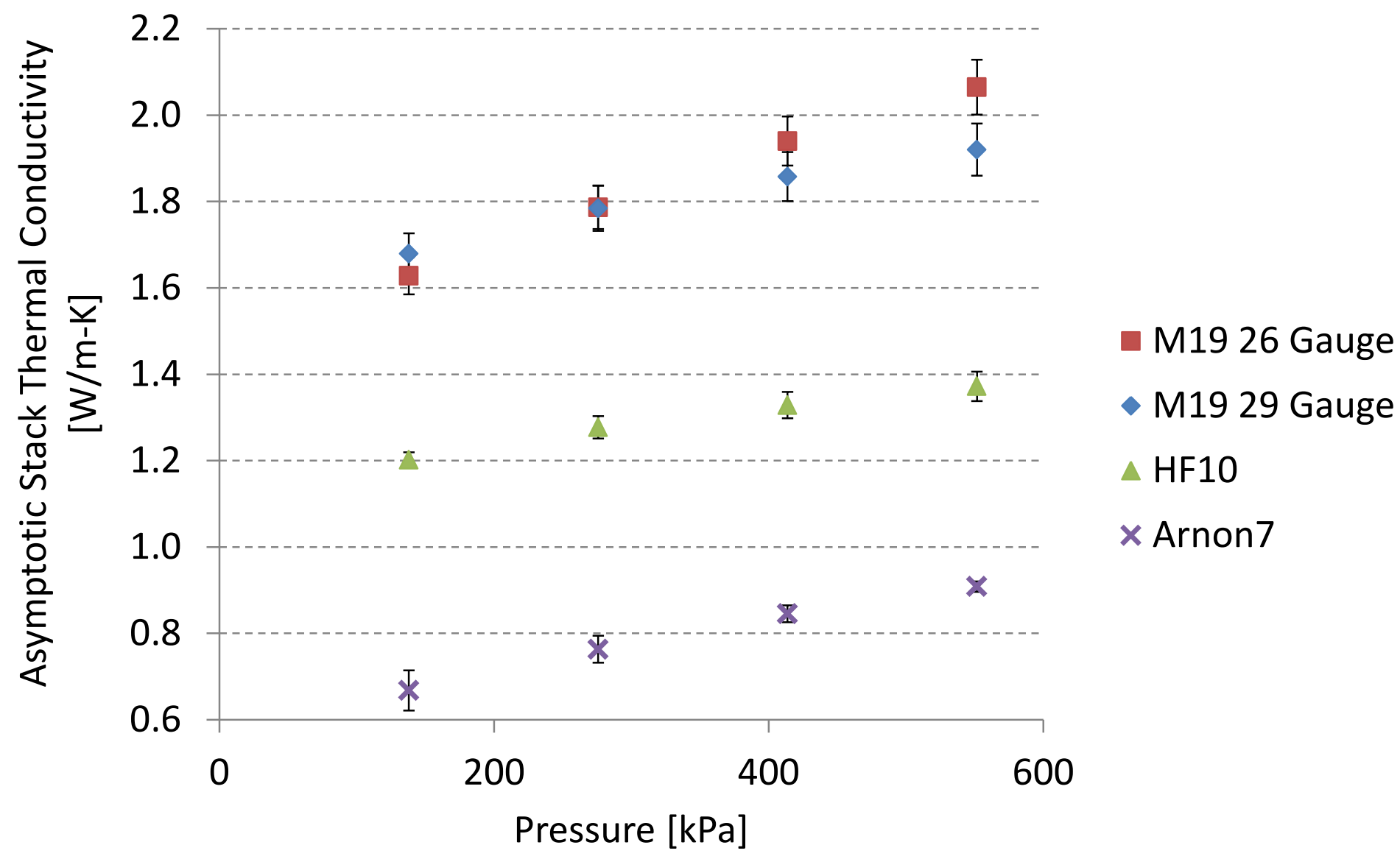

Error bars represent 95\% confidence level 


\section{Transverse Winding Thermal Conductivity}

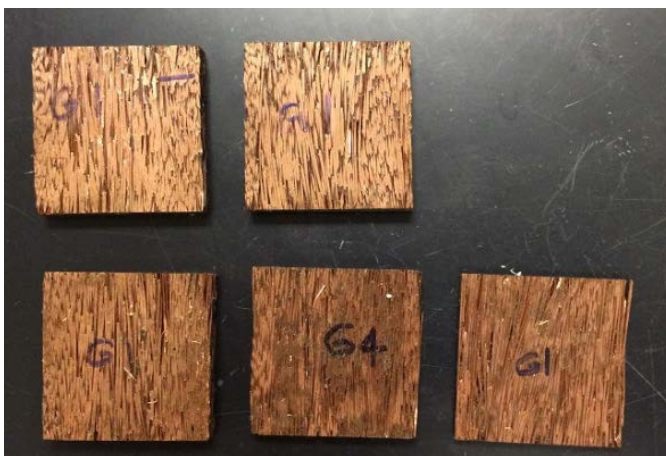

Photo Credit: Emily Cousineau, NREL

\section{AWG Transverse}

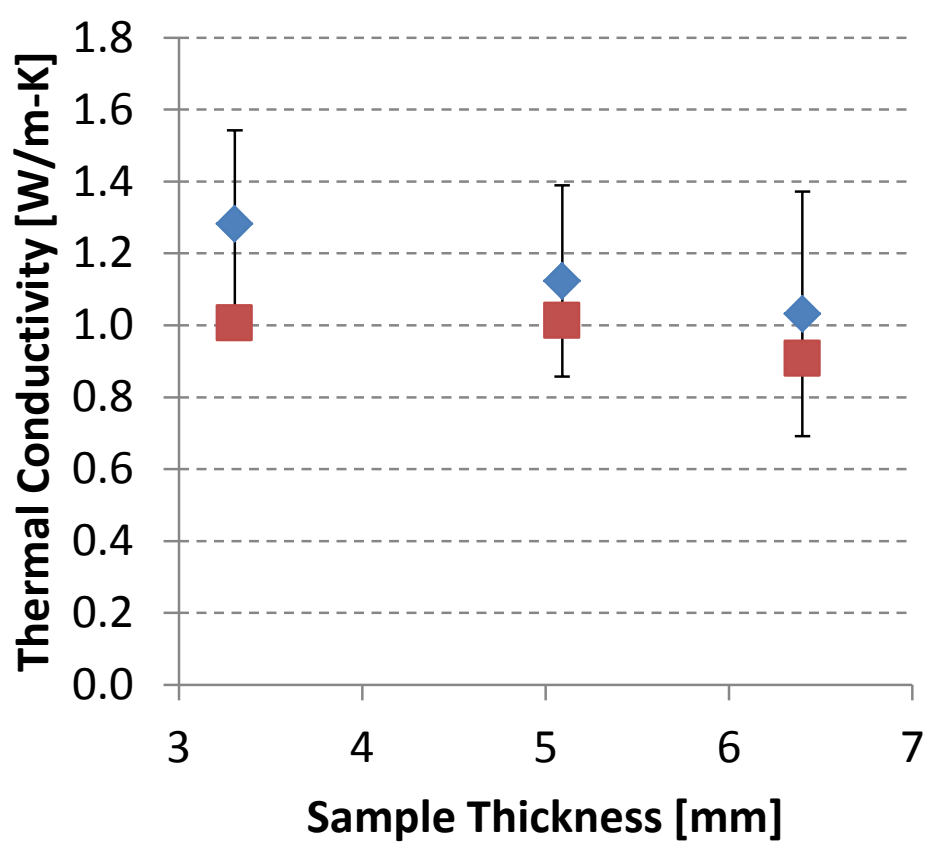

19 AWG Transverse

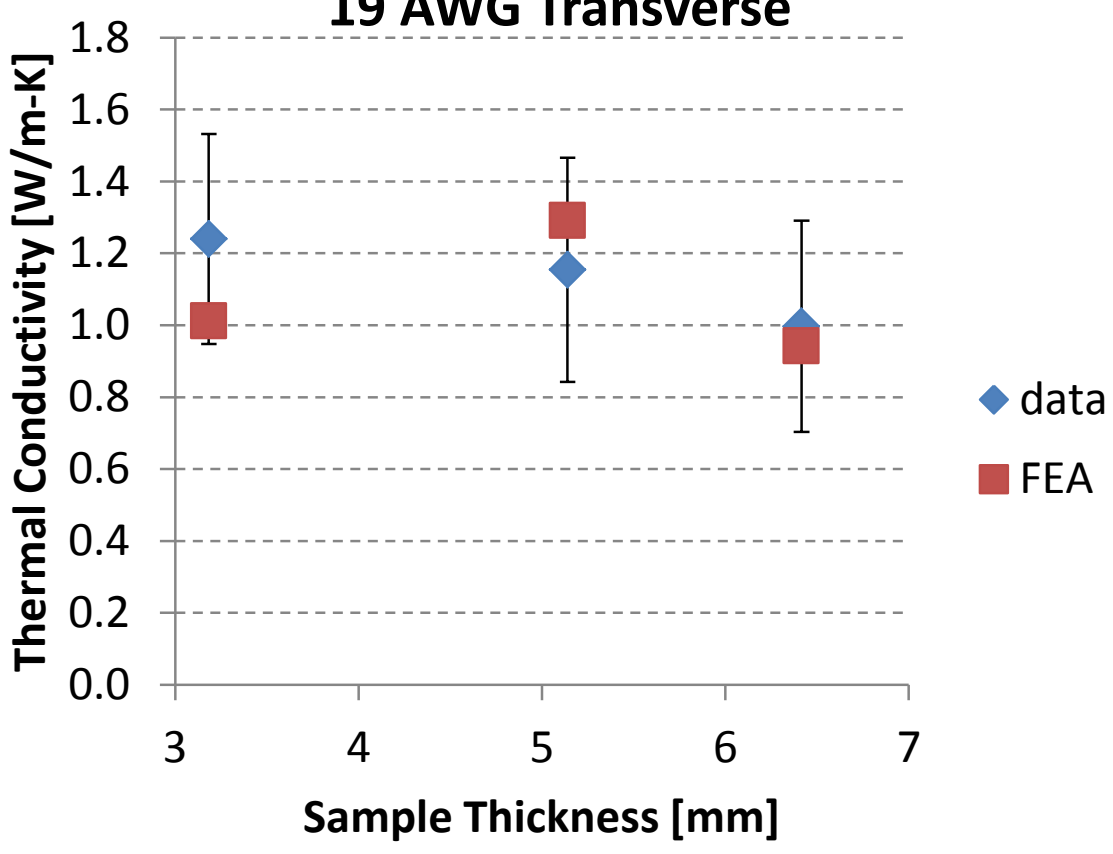

- data - Error bars represent 95\% measurement uncertainty (U95)

- Finite element analysis (FEA) model results based on measured sample copper fill factor

- FEA assumes hexagonal or closed-pack wire pattern 


\section{Participation in Industry-Led Projects}

- Industry-led inverter development with VTO and AMO funding

- Delphi Inverter (VTO)

- GM Inverter (VTO)

- Wolfspeed Wide-Bandgap Inverter (VTO)

- John Deere Wide-Bandgap Inverter (AMO)

- UQM Technologies motor development (VTO funding) 


\section{Summary}

- Low-cost, high-performance thermal management technologies are helping meet aggressive power density, specific power, cost, and reliability targets for power electronics and electric machines.

- NREL is working closely with numerous industry and research partners to help influence development of components that meet aggressive performance and cost targets

o Through development and characterization of cooling technologies

o Thermal characterization and improvements of passive stack materials and interfaces.

- Thermomechanical reliability and lifetime estimation models are important enablers for industry in cost- and time-effective design. 


\section{Acknowledgments:}

Susan Rogers and Steven Boyd EDT Program Vehicle Technologies Office Advanced Manufacturing Office U.S. Department of Energy
For more information, contact: NREL APEEM Section Supervisor

Sreekant Narumanchi sreekant.narumanchi@nrel.gov Phone: (303) 275-4062

\section{Industry and Research Partners}

Ford, GM, FCA, John Deere, Tesla, Toyota, Oak Ridge National Laboratory, DARPA, Virginia Tech, University of Colorado Boulder, University of Wisconsin, Carnegie Mellon University, Texas A\&M University, North Carolina State University, 3M, NBETech, Curamik, DuPont, GE Global Research, Semikron, Kyocera, Sapa, Delphi, Btechcorp, Remy/BorgWarner, Heraeus, Henkel, Wolverine Tube Inc., Wolfspeed, Kulicke \& Soffa, UQM Technologies Inc., nGimat LLC 